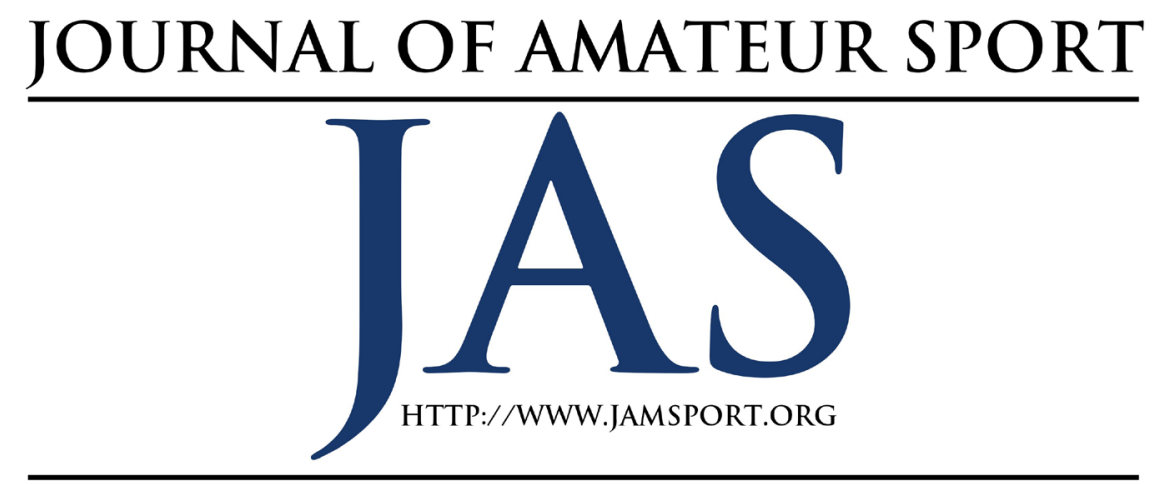

\title{
Perspectives on Native American Imagery from Students at a Premiere Tribal University
}

\author{
Zach Scola ${ }^{1}$ \\ Brian S. Gordon ${ }^{2}$

\section{${ }^{1}$ University of New Hampshire \\ ${ }^{2}$ University of Kansas}

Zach Wilkerson ${ }^{2}$

$\mathrm{I}$

n 2005, the National Collegiate Athletic Association (NCAA) announced a "policy prohibiting colleges or universities with hostile or abusive mascots, nicknames, or imagery from hosting any NCAA championship competition" (NCAA Executive Committee, 2005; para. 4). Schools that displayed any hostile or abusive imagery on their mascots, or their uniforms, including the team's cheerleaders, dance team, and band, were barred from wearing that material at NCAA championships in the future. This NCAA policy forced the hand of many teams, nearly all of whom had to make changes regarding their mascots or behavior (Mungia, 2014).

Beyond the many popular college teams, there are also over 2,000 high schools that use Native American im- agery (Mungia, 2014). Native American imagery has consistently been found to negatively impact young Native Americans (Davis-Delano et al., 2020; Fryberg et al. 2008; Moscovici, 1998), and much of this research has surfaced since the statement made by the U.S. Commission on Civil Rights. The U.S. Commission on Civil Rights (2001) specifically stated, "The stereotyping of any racial, ethnic, religious or other groups when promoted by our public educational institution, teach all students that stereotyping of minority groups is acceptable, a dangerous lesson in a diverse society" (para. 4).

The specific case of Haskell Indian Nations University (HINU) presented unique circumstances in which to further investigate the social impact of the usage of Native American imagery. HINU is 
one of two intertribal colleges operated by the U.S. Federal Government and the lone four-year university (Bureau of Indian Education, n.d.). According to articles in school newspapers ranging from 1963 to 1995 , HINU was given the athletic team name of the Indians by local and regional newspapers as a way to describe the athletic participants of the school. In the 1960s, HINU sought to create an identity of its own by renaming the athletic teams to the Braves. After a lack of support for the new name and a general lack of acceptance by school supporters of the new team name, HINU decided to revert to the team name of the Indians in the 1970s. In 2020, the Indian Leader Association conducted a survey asking if HINU should change their mascot. The preliminary results showed a nearly even split between students, alumni and faculty (Nally, 2020). Interestingly, $77 \%$ of other community members (parents, other $\mathrm{Na}-$ tives, Lawrence residents, etc.) voted yes, they should change the mascot.

The main entrance to campus is adorned with a large stone sign emblazoned with the Fightin' Indians logo, which is of a male Native American wearing a headdress, and the Haskell Indian Nations University name. As one moves through campus it becomes apparent that all the buildings and streets on the Bureau of Indian Education are named after significant Native people and tribes. From Pocahontas Hall, to Kiowa and Shawnee Avenues, and finally to the Thorpe Fitness Center, the campus is rich with history relevant to Native culture and has embraced their cultural and historical significance. On the far east corner of campus, one would approach the Coffin Sports Complex, named after former coach and Athletic Director Tony Coffin. Next to the main entrance to this facility stands an over 10-foot-high tile mural adorned with the Fightin' Indians logo. Once inside, there are numerous glass display cases containing memorabilia throughout the gym foyer, celebrating the many past athletic success of Native students at Haskell. Walking through the gym doors, fans will be greeted once again by the Fightin' Indians logo across center court. The logo and team name seem intertwined with the history of the university as it is prominently displayed and certainly viewed as a part of Haskell's tradition and history.

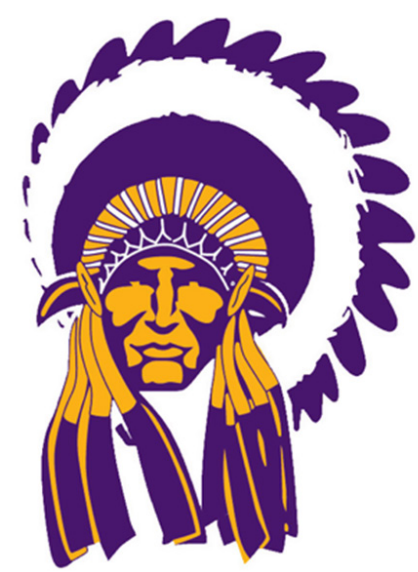

\section{HASKELL INDIAN NATIONS UNIVERSITY}

Figure 1

$$
\text { Haskell Fightin' Indians logo }
$$

HINU seems to stand as a contradiction to the U.S. Commission on Civil Rights (2001) denouncement of the usage of Native American imagery. The commission stated that the cultural misrepresentation of the mascots and im- 
agery stands as the main opposition for the denouncement. HINU does have a unique history in regard to Native imagery and their team name. The school was originally opened in the late 1800's as a boarding school and along with other similar schools was utilized to assimilate Native American youth into white culture (Schmidt, 2001). Additionally, a former Haskell football coach played a big part in the former team name and logo of the Washington football team of the National Football League (Hylton, 2010). One aspect that makes this case study interesting is that HINU's websites communicates they seek to implement Native culture into their curricula (School History, n.d.) and that their athletic department should represent the Native American cultures their students come from ("Athletic Mission," n.d.).

Research previously focused on the potential insensitivity and misapproproation of Native American culture through the usage of Native American imagery by outside sources (Burkley et al., 2017; Davis-Delano et al., 2020; Staurowskey, 2007), but none examined how perceptions might be altered if the usage stemmed from a Native American institution, which make HINU a facsinating case to explore. It is valuable to not only see how a Native American institution views their own Native imagery, but to consider how these students think the imagery may influence outsiders. Native imagery has been frequently found to produce many negative effects (e.g. lowered self-esteem, lessened potential of future self), however understanding how this specific insituition differs from other usage is important. The case of HINU provided the researchers with the inimitable chance to further investigate both potential sides of the issue. Therefore, the purpose of this study was to examine how HINU students feel about $\mathrm{Na}$ tive American imagery overall and their perceptions when institutions like HINU use Native American imagery.

To examine this unique and specific usage of Native American imagery, the authors considered a great deal of past research on the topic. Specifically, the authors relied on past work which evaluated how this imagery may impact Native American's cultural identity, stereotyping of Natives, and social representation theory and the way this imagery may impact how Native's reflect towards themselves. This broad lens helped influence the manuscripts methods and influenced the discussion.

\section{Literature Review}

\section{Cultural Identity}

Cultural identity refers to a subset of social identity and is defined as feeling of attachment a person has to a cultural group's ideals and values (Ferguson et al., 2017 Schwartz et al., 2010). Shepard and colleagues (2018) stated a positive sense of cultural identification may "provide an individual with a sense of belonging, purpose, social support and self-worth" (p. 1). Persons tend to associate with a particular group, which is described as, "a set of individuals who share the view that they are members of the same social 
category" (Burke \& Stets, 2009, p. 118). Moreover, two processes including social comparison and categorization initiate the development of a category perceived as "ingroup" by a person (Burke \& Stets, 2009). According to Mullen and Goethals (2012), a group represents a collection of individuals who perceive themselves as members of a particular social category, are motivated by a rewarding social stimulus, are interdependent on the interaction with one another, and tend to influence the thoughts, beliefs and actions of one another.

Ethnic identity is described as an element of adult identity formation which occurs during childhood years (Fisher et al., 2017). This process traces back to Erikson's (1968) work on identity development who believed one's identity is formed when they make a commitment to their choices with regard to identity. Lewis and colleagues (2018) found that the thoughts, beliefs and actions associated with one's ethnic identity significantly influence individual decision making in integral life choices. The cultural and societal perceptions of individual ethnic identity have even been found to negatively influence the behavior of adolescents when exposed to these societal perceptions (Bleakley et al., 2017). Given the relevance of an individual's perception of others, it is important to be familiar with the processes associated with stereotyping.

\section{Stereotyping}

Posten and Mussweiler (2013) described stereotyping as "a crucial mech- anism that frequently shapes our judgments and allows individuals to form impressions of others even when judgment-forming circumstances are taxing" (p. 568). Stereotypes are a very consistent part of human discourse and are impacted greatly by the media (Bleakley et al., 2017; Fryberg et al., 2008). Fryberg et al. (2008) stated that stereotypes can form the common public perception of a group of people when the group is being represented by the stereotype that is generally unfamiliar. Most Americans do not have any personal experience with true Native American culture (Fryberg \& Eason, 2017; Masta, 2018). Therefore, the mere exposure to Native American mascots has been found to increase the activation of negative stereotypes (Davis-Delano et al., 2020). Stereotype activation is the process of instinctively, and possibly unintentionally, stimulating a stereotypical thought or idea in the mind (Burkley et al., 2017) and research suggests that Native mascots and logos may trigger these thoughts towards Native Americans.

Kelly (2017) demonstrated the inherent issues with popular culture and mass media trying to accurately and appropriately represent Native American culture as there is no uniform way to do so and it's regularly inaccurate. The systemic and longstanding representation of an entire culture as a caricature and a mascot has made it seem as Native culture and in turn Native Americans are merely a vestige of the past (Kraus et al., 2019; Leavitt et al., 2015). Further, the lack of correct representation of Native culture 
for many people essentially enhances these misrepresentations (Fryberg \& Eason, 2017). The institutionalization of this notion then makes it possible to analyze the intricate connections between Native American identity and the stereotypes appropriated by mascots and imagery (Fryberg et al., 2021). Stereotypical representation in popular culture and mass media may serve to hinder and limit the self-understanding and perception of what it means to be Native American for Native American youth (Leavitt et al., 2015).

\section{Social Representation Theory}

According to Fryberg et al. (2008), social representations are essential to the study of Native American imagery in sport given that they "help individuals make sense of their past, present, and future by providing a shared language" (p. 210). Social representation theory, in the case of imagery usage in sport, is operationalized to discover how specific words, images and symbols that are taken for granted or considered the norm can greatly influence public perception of whatever they represent (Fryberg et al., 2008). Specifically, regarding Native American imagery, many scholars have stated that even if these Native American mascots are viewed positively, there may be negative consequences because of the limited variability of Native American representations, which can limit what young Native Americans see as possible for themselves in the future (Fryberg et al., 2008; Kraus et al., 2019; Leavitt et al., 2015).
Fryberg et al. (2008) investigated the idea that the widespread usage of Native American imagery could have negative effects on young Native Americans. The scholars conducted four studies and found that high school students felt depressed self-esteem and lowered selfworth when exposed to specific Native American images. The scholars also found that college students felt fewer achievement-related possible selves, which they describe as "selves are images of the self that one hopes to become; they motivate sustained goal-directed behavior and are important for the attainment of future goals" (p. 214). The findings of the aforementioned study serve as a foundation for developing an understanding of how Native Americans might react to the social representations of themselves through Native American imagery in sport.

Scholars who strongly adhere to the social representation theory, may argue that all organizations should cease the usage of Native American imagery (Burkley et al., 2017; Fryberg et al., 2008; Fryberg et al., 2021). These scholars found this imagery to have negative effects on high school and college students, especially regarding lowering possible self-images of what they believe they could become (Fryberg et al., 2008). These findings align with scholars and popular press examinations of specific imagery, where it began, and how Natives and others have protested its usage. 
Native American Imagery and Symbolism

The inappropriate or inaccurate use of Native American imagery with sports teams has been a contested issue for many years. For instance, Native Americans have protested against the Cleveland Indians and their mascot "Chief Wahoo" for years, and in 1970 The University of Oklahoma retired their mascot "Little Red" because of the misrepresentation of Native American culture (Schwarb, 2016). Professional teams such as the Washington Redskins and Cleveland Indians have received a lot of publicity for their team names, logos, and mascots being misrepresentations of Native American culture, but Native American imagery is being used by a great deal of educational institutions (e.g., higher education and secondary education).

The use of sport team logos has been evaluated by equating the logos to symbols (Callais, 2010). Viewing logos through this lens, means that literature focusing on symbolism and symbolic interactionism can be used to properly assess team logos and team names. Carter and Fuller (2015) described symbolic interactionism as a social behavior related to the interpretations of symbols. Through selective framing, it is entirely possible that individuals interpret these symbols in different ways (Carter \& Fuller, 2016). Callais (2010) stated that these contradictions in perceptions create symbolic conflict. The researcher found that the incongruity of evaluations of the symbols often correlate to the racial reference point of the evaluator.
Previous academic research has not only scrutinized the perceptions of Native American imagery, but also the possible impact that it can have on individuals. Davis-Delano et al. (2020) found that this imagery is psychologically detrimental to Native American children. Adams and colleagues (2006) interviewed students at HINU to delve deeper into their individual thought processes on $\mathrm{Na}$ tive American identity. Researchers found that despite the fact that each student at HINU was Native American, the individual responses varied greatly. Steinfeldt and Wong (2010) explained the possibility of multi-cultural education changing public perception of the usage of Native American imagery. Their results showed that the educational intervention increased an awareness of issues and potential racism associated with a variety of Native American mascots and team logos. Fryberg et al. (2008) examined the potential factor of the stereotypical emphasis on Native American "warrior culture" on the individual mindset of Natives.

This negative impact on Native Americans was certainly considered when the NCAA passed legislation to restrict Native imagery, but even as they did this, they partnered with numerous corporate sponsors who implemented Native imagery (i.e., Pontiac) (Staurowsky, 2007). Many people may have thought Native imagery to be "acceptable" because of the prevailing notion that Native American's did not find it offensive, which was supported by the Washington Post in 2016 with a poll suggesting up to $90 \%$ of $\mathrm{Na}-$ 
tive American's felt this way (Fryberg et al. 2021). However, Fryberg et al. (2021) conducted a large scale, much more representative study that found $49 \%$ of Native American's surveyed found the imagery offensive and 13\% were indifferent. It is important to understand that this imagery may indeed be offensive to Native Americans as a first step in educating the general population. This work transitions the thought process from the potential influence of Native American imagery on the individual mind and into the realm of the potential amplification of stereotyping associated with the usage of Native American imagery.

\section{Methodology}

\section{Research Design and Participants}

The study was grounded in social constructivism, where the participants are given the ability to share their own stories and the findings would be discovered through their own lived experiences (Kim, 2010). Guba and Lincoln (1994) recognized the social constructivist approach to consider each individual's personal experiences, with all person's stories being very specific and unique in nature. All interviews were conducted between April and June 2017. This case study was conducted through semi-structured interviews with students at Haskell University, specifically with students recruited from the American Indian Studies department. The students were selected from this group because the authors wished to understand how students, who are highly identified with their Native
American culture, feel about Haskell's imagery in contrast to other institutions usage of Native American imagery. The sample was purposeful which is appropriate when the desire is to gain a deep understanding of a specific culture (Tongo, 2007).

The semi-structured interviews allowed core questions to be consistent and for follow-ups questions to be presented based on participant responses (Gratton \& Jones, 2004). The questions explored responses through a phenomenological approach, where the authors wanted to consider the human experience and attach meaning to those experiences (Merriam, 2009). The interview prompt was seven broad questions with potential follow up questions embedded (see Appendix 1). However, the goal was to allow the conversation to flow organically and the prompt was used only as a base for the discussion. Given the nature of the study, researcher positionality is important to address (Guba \& Lincoln, 1994). The secondary researcher who conducted the interviews was an instructor at Haskell, a Native American. The background of this researcher helped ease the participants and allowed them to open up about their experiences as a Native American.

The study consisted of 14 students from Haskell. Interviews were conducted with eight female students and six male students and their time as a student at Haskell ranged from three semesters to nine semesters (See Table 1). The goal of these interviews was to explore how students at Haskell view Native American 
Table 1

\section{Participants Backgrounds}

\begin{tabular}{ccc}
\hline $\begin{array}{c}\text { Participant } \\
\text { pseudonym } \\
\text { Allen }\end{array}$ & Gender & $\begin{array}{c}\text { Semesters } \\
\text { at Haskell }\end{array}$ \\
Timothy & Male & 9 \\
Beth & Female & 8 \\
Jackson & Male & 7 \\
Annabella & Female & 6 \\
Adam & Male & 3 \\
Isabella & Female & 4 \\
Kenny & Male & 8 \\
Jackie & Female & 8 \\
John & Male & 8 \\
Jade & Female & 6 \\
Laura & Female & 6 \\
Kaitlyn & Female & 6 \\
Melanie & Female & 6 \\
\hline
\end{tabular}

imagery overall and additionally to see if these students felt Haskell's imagery is more appropriate and effective than imagery used by non-tribal institutions.

\section{Procedure}

After Institutional Review Board (IRB) permission was granted, the semi-structured interviews were conducted and audio recorded. Each participant was asked uniform questions proceeded by follow-up questioning in specific circumstances to help guide the interview (Petty et al., 2012). Questions were developed to obtain responses from participants to gather their insight on a variety of issues regarding the use of Native American imagery. Topics ranged from how Native American imagery has impacted their life, to how Native American imagery used at Haskell is different from that used at non-tribal institutions. Examples of questions included: How do you feel about the usage of Native American imagery for schools and sport teams, and do you think there is a difference between Haskell's imagery and any high school/college using similar imagery (see Appendix 1 for full prompt)? Following the completion of the interviews, the authors transcribed the audio recordings.

\section{Analysis}

After the completion of transcriptions, authors separately coded the transcriptions looking for common themes. This was conducted using DeCuir-Gunby et al.'s (2011) steps for creating a codebook. For this study the authors utilized theory-driven (deductive) and data-driven (inductive), meaning themes may emerge from the raw data as well as from the project's goals and from ideas brought to the table by the past literature (DeCuir-Gunby et al., 2011). Codes based on past literature were reviewed and edited within the new data and codes that developed directly from the data were broken into multiple subthemes which were compared across other subthemes before specific codes were depicted (Decuir-Gunby et al., 2011). At times, where transcriptions needed clarification, member checks were conducted with participants. Throughout the results section for the sake of anonymity, pseudonyms will be used (noted in Table 1). To aid the researcher's reliability and validity, the authors utilized five verification strategies from Morse et al. (2002) which includes: (1) methodological coherence, (2) appropriate sample population, (3) 
collecting and analyzing concurrently, (4) thinking theoretically, and (5) theory development.

\section{Results and Discussion}

The authors identified multiple themes that reflected how the students at Haskell felt about Native American imagery. This section addresses the two main themes of the study, HINU students' feelings about Native American imagery overall and their feelings about HINU's usage of Native American imagery. Each theme, and its subsequent subthemes, are addressed with numerous representative quotes and then discussed in more depth. This section finishes with practical implications, limitations, directions for future research, and a general conclusion.

\section{Feelings about Native American Imagery}

One goal of this study was to address how these students felt about Native American imagery with other sport teams and products. The over generalization and stereotypes of these non-native institution's imagery was consistently discussed in the interviews. Additionally, students also felt this imagery impacted them and their friends/family negatively. Each of these themes were consistent throughout the interviews.

\section{Generalization and stereotyping of Native Americans}

During the interviews, the students were asked about the Cleveland Indians, Washington Redskins, Florida State Seminoles, and numerous local high school teams that the students mentioned. While discussing the Cleveland Indians, Isabella described her distaste and the harm she thinks it may cause: "I think it's hideous and a huge ugly stereotype what the dominant culture thinks of us, and it doesn't help with any sort or relations between Indians and non-Indians at all." The concept that these images were stereotypes was found throughout the interviews with these Haskell students. The students found the Cleveland Indians logo especially stereotypical because of its caricatural nature due to the red skin, large nose, and the feather in his hair. Another student went as far to say that the stereotypical Haskell imagery, which was viewed as much less offensive throughout the interviews, might have an impact on how outsiders view Native Americans:

Yes, I think people look at that and see a stereotypical Native, and all Natives become that to them. Then, it's not that much of a jump to say, if that's correct then all the other stereotypes are too.

It was apparent that these students felt Native American imagery could be damaging and that it could reinforce or create stereotypes of Native American people. In another sense, a student discussed how she found Native American imagery disgusting because of how it treats $\mathrm{Na}$ tive culture as something of the past and not as a current culture:

I find it distasteful, because it kind of just makes the argument that we are not really there anymore and that we are just a part of 
history. That is something that as Native people, we have to combat all the time, that we are not just a part of history and that in fact we are still here. To be used as mascots and having those mascots to represent us in the way that we don't want to be represented and everything that comes from that. We aren't that, we are people. We are not a logo. We are not this 2-D form. We are actual living beings with complete diverse cultures. To just be summed up as this Redman Indian on the side of football helmets, an aggressive sport, that's just distasteful.

Using an entire culture of people as imagery for sport teams and schools was not seen as appropriate throughout the interviews, despite the idea that emerged that if done correctly it could possibly be empowering for Native Americans. The fact that students found blatant stereotypes such as the Cleveland Indians and the Washington Redskins to be damaging and offensive was not surprising. Additionally, the students related personally to how this imagery impacted themselves or other Native Americans.

\section{Effect on a Personal Level}

The Haskell students also addressed the potential effect that the usage of Native American imagery might have on Native American people. Students were directly prompted to discuss any instances where they felt like they were personally, either directly or indirectly, impacted by the usage of Native American imag- ery. While students often referenced the stereotypical nature of Native American imagery, understanding how the individual students might have personally been impacted by the imagery was important.

When asked if the usage of Native American imagery had had any impact on them personally, one student echoed what many suggested and stated, "not on me in particular, but I know some friends and colleagues that really take offense and it kind of hurts them." This quote briefly touched on how the usage of $\mathrm{Na}$ tive American imagery might impact the attitudes or self-esteem of Native American people by referencing how friends or colleagues are hurt by the images. Other students discuss how the usage of imagery influences stereotypes held by the general public. Adam provided the following representative quote when speaking about imagery:

I mean, it's always gonna (sic)

like keep the stereotypes alive.

That's the thing about it, even like walking around some places and if you're recognized as a Native they'll do a wahoo or Hollywood style type of stuff to you.

This quote provides potential context into how Native American imagery may be creating or perpetuating negative stereotypes of Native American people. These students provided examples of being bullied for being Native American and either directly or indirectly credited this imagery in some capacity.

However, in a broader argument discussing the potential impact of the creation of stereotypes, Beth referenced 
a usage of Native American imagery unrelated to sport:

Me personally, I do think that it is damaging. As a Native woman, you can't ignore that when $\mathrm{Na}$ tive females are oversexualized in cartoons or imagery for even just a campaign or a trademark for a butter logo, it affects us. It shows in statistics that 1 in 3 of us are sexually harassed... I believe that it has a negative impact on how we are treated by larger society and sometimes how we treat each other.

The student did not directly reference sport-related images, but the example that she provided gives similar insight into the potential stereotyping and the resulting negative repercussions of the stereotypical portrayal of Native culture. Many students did not specifically feel targeted by peers because of being $\mathrm{Na}$ tive American but did discuss ways they thought their family/friends and Native overall were stereotyped. The imagery in question was considered a strong catalyst in the stereotyping towards Native Americans. Additionally, many were aware of statistics discussing the ramifications of these stereotypes aided by this imagery.

Drawing from past research it came as no surprise that these students viewed Native American imagery negatively. Scholars have suggested that Native American imagery may limit young Native American's view of their future selves (Fryberg et al., 2021; Fryberg et al., 2008) and can go as far as having psychological damage to Native children (Delano et al., 2020).
The stereotypical and over generalized imagery may form the public's perception of Native American's, but it also appeared to have potential negative implications for these young Native Americans. The students in this study suggested even well intentioned Native American imagery would not be representative of all Natives and therefore an overgeneralization. Fryberg et al. (2008) found that young Native Americans felt depressed self-worth when exposed to certain Native American imagery and our subjects appeared to feel much distain towards the more offensive imagery of the Indians and Redskins.

The authors probed about their experiences as a Native growing up because of previous work which found that the usage of Native American imagery had a potential negative impact on the self-esteem of young Native-Americans (Fryberg et al., 2008). The findings of Fryberg and colleagues (2008) directly stated that participants reported lower self-esteem related to their views of Native American imagery. Since stereotypes are known to be influenced by the media (Bleakley et al., 2017) it makes sense that the Haskell students attributed some hardships they witnessed growing up to the Native American imagery used by non-Native entities. Even the Haskell students in this study who discussed no negative stereotyping experiences growing up, attributed much of these issues overall to the usage of Native American imagery by sport team and other products.

King (2010) discussed how mascots were originally predatory and dangerous 
animals, then later were human groups known for their violent behaviors. Most recently he noted the trend of creating team names around the nostalgic violence associated with "cowboys and Indians." Violence seems to be the vocal point of many mascots, therefore depicting a living race as a team's mascot may lead to blatant stereotypes. As these stereotypes can create a common perception with the public (Fryberg et al., 2008), it is very important to understand how Natives impacted by these stereotypes believe they are being perceived. These Haskell students felt that much of the Native American imagery being used was stereotypical. These stereotypes included the Indians logo with the red skin and large nose, as well as the idea that all Native Americans may be Plains Indians, as many tribes do not wear headdresses or war bonnets yet most of the imagery depicts them as such. The findings suggesting that these students felt much of Native American imagery to be stereotypical and disrespectful was not surprising. However potentially in contrast, a 2020 survey found that only approximately $50 \%$ of HINU students, alumni and faculty felt that Haskell's mascot should be changed (Nally, 2020). The most novel findings of this study revolve around the contradictory findings regarding how they felt about Haskell's imagery.

\section{Haskell's usage of Native American Imagery}

Throughout the interviews, students discussed how Haskell's imagery differed from other organizations usage of $\mathrm{Na}$ - tive American imagery. They discussed how being an all Native university made their imagery more appropriate and less offensive based on the ownership they felt. Counter to the first finding, students also discussed how even Haskell's well-intentioned imagery was not representative of all. Additionally, the students also discussed how an all-Native American university's Native imagery may impact outsiders perceptions.

\section{Ownership over the Native American Imagery}

At times, the students felt that being an all Native American institution alone made their usage of the imagery more appropriate. Allen described how he felt growing up with Native American imagery at schools:

Well I grew up competing against other schools with Native American imagery, mascots that were Warriors or Indians. To me I thought with a Native American school using that it would be used in a good, positive way, as it's actually representing who we are as Native Americans. This student was describing how he assumed Native schools would do a more appropriate job of representing Native American culture when they used this imagery. This idea was felt throughout the interviews, as students felt it was acceptable for an all-Native school, such as Haskell, to utilize Native American imagery and names.

John explained how some usage of Native American imagery could possibly be empowering while discussing his 
feelings of Native American imagery in general:

I feel like aspects of it are disrespectful, so I feel like if you're using say...like Redskins is disrespectful, but if you're a Native school and you're called the Braves that can be more, empowering. The idea that being an all-Native school and representing their culture through their imagery and team name was appreciated throughout the interviews. Isabella detailed this and added that who was controlling the imagery was important, when discussing Haskell's imagery:

I think there's a difference because we are the ones that are using it and controlling our images. And I don't really think we have anything equivalent to the tomahawk chop or any of the stupid headdresses, because we know about our history and the usage of it. So, I think Native schools and Haskell, in particular, know how to respectfully portray it I guess, which is not the same for the Cleveland Indians.

This student was giving Haskell credit in the sense that they (students, administration, and the fans who attend sporting events) would be able to appropriately portray their Native American culture, whereas non-Native organizations do not have the knowledge to do so.

Ownership was the key factor in students' belief that Haskell had the right to use Native American imagery even if non-Native organizations should not, and this was depicted well by Melanie:

Yes, because at Haskell we are 100\% Native Americans. We come here. This is our history. If we want to represent ourselves, as Natives, and we are the Haskell Indians, we kind of essentially have that right to because everybody at this school is part of, or a member of, a sovereign nation. Whereas, if it was just a non-Native using an Indian logo, it is just distasteful. You are not Native. You don't know the culture. You don't know what being Native American is like.

It was very apparent that Haskell being a Native American institution warranted them the right to use Native American imagery for their team name and logo.

There was discussion that contradicted this ownership, based on how others are expected to change their imagery and the fact that it's not representative of all Natives, "I mean, if we're going to make the other schools change their name, I believe we should have to change ours. Yes, we are an all native school, but it's basically the same thing" (Timothy). This student felt it was almost hypocritical for Haskell to use Native American imagery while many protest and dispute other organizations usage of the imagery, and these feelings were apparent throughout and align well with the seconding finding.

\section{Representative of who?}

Despite the ownership students agreed Haskell had over their Native American imagery, they also discussed how their more appropriate imagery only represents certain types of Native Americans. Jackie described how using Haskell's logo, which depicts a Plains Indian, 
could influence outsider's assumption that all Native Americans are like that one logo:

Here we're not all the plain Indians that wears a war bonnet, we've got our Alaskan Natives, many other tribes, we're not just indigenous to them, so that is honestly a misrepresentation. So being an outsider, and if someone see this, oh the Haskell Indians that's their logo, all Indians must have war bonnets.

It was apparent that students felt even the Native American logos that were respectful were still too general and, in a sense, create an idea that their entire culture could be represented by this one image.

Beth addressed how these schools and teams always use male Native American imagery, when discussing the impact Haskell's imagery could have, despite her feelings that a woman may be more representative of her culture overall:

One of the biggest issues I have with it is with who created it. It is a stereotype. It is still very patriarchal. It is of a man. Most of our societies are matriarchal. Honestly, if I tried to find a logo to represent the Navajo tribe, I would put a woman, because we come from them. When you look at most of the representations that Natives create themselves it is with a woman. The Black Snake, many of the shirts that came out of there used a woman. You see all of this empowerment and it is of a wom- an giving life with corn or with water. I think that when that logo was created it was a time when many people still had this colonized mind and it influenced the decision. I think they can educate people on it, but it still enforces some kind of colonized, masculine identity of Natives.

It was obvious that despite the attempt of schools to use more respectful and appropriate imagery that these students still felt the imagery was too general and should not be used to define an entire culture. Melanie summed up the idea well, stating that these images are not representative of most Native American cultures in his answer regarding if Haskell's imagery was representative:

No, because not all Natives wear headdresses. Not all Natives have these flairs. I mean, this is just simplifying this mascot into one kind of, one kind of Natives. There are the Plains Indians. There are the Southwest Indians. There are the Alaskan Natives. There are all these regional Natives and being summed up in this that doesn't represent everybody's cultures. I think it is mostly Plains-ish. Even when teams and schools are trying to use "respectful" imagery for their $\mathrm{Na}$ tive American mascots and team names, these students still had concerns. The students described logos like Haskell's too generalized and not representative of Native culture overall. It was very apparent that these students from Haskell felt even the most well intentioned Native 
American imagery often is not representative of their culture and this could lead to confusion for outsiders.

\section{Potential Impact on Public Perception}

The students discussed the role that Haskell's usage of Native American imagery might have in the broader conversation revolving around the concept of Native American imagery. As previously discussed, Haskell's standing as an all-Native institution has been referenced by students as one of the main aspects that differentiates it from others. This differentiation also serves as the key reasoning behind the elevated importance of Haskell's usage of Native American imagery.

During the interview process, students discussed the ownership of and perceived authority on the issue of $\mathrm{Na}$ tive American imagery. Jade provided this representative quote:

Yes, I think that they might see it is as us being hypocrites. Like, well if you guys are the Indians and this is your logo then obviously it is okay to use and have it be out there. So, I feel like that does have an impact on the outside view The student suggested that Haskell's use of the imagery implicitly endorses the usage of Native American imagery by any other organization or institution. The hypocritical nature the student refers to was prominent throughout the interviews as students did see the irony in Haskell's usage of Native American imagery.

Kaitlyn alluded to the racial and cultural connection of the university and the potential influence that the connec- tion plays in influencing public opinion: Basically, it's okay for us and not you all pretty much. They would say something [like that], but every race would do that. I don't know how else to say it, kind of like Halloween there are like outfits for being a Mexican. Like yeah, it's okay for a Mexican to wear that, but is it okay for another race to do that? It's the same thing. You know what I mean?

Kaitlyn provided an example arguing that Haskell being an all-Native American institution gives them authority on Native American imagery. Melanie further corroborates this assertion, when she stated the following:

Somebody out there is always just going to be like yeah if they are using it, it is going to be okay. Essentially if they are reducing themselves to that, then it is okay for us to do that... I think that does have some impact to the greater population being like if they are doing it then it must be okay. There is some context to it though.

This emphasizes the concept of self-representation and how, as a solely Native American university, Haskell can choose to represent themselves to the public however they see fit. However, the students also acknowledged that self-representation through the usage of this imagery might impact the public view of other organizations or institutions also using similar imagery.

After analyzing the quotations above the authors discovered parallels with past work and unique findings that warranted 
discussion. There is a concern among scholars who have studied Native American imagery that the stereotypes presented will negatively impact both the overall public's perception of Natives as well as the self-esteem of young Native Americans (Davis-Delano et al., 2020; Fryberg et al., 2008). If it is true that Native American imagery may have a negative psychological impact on Native youth (Davis-Delano et al., 2020), then understanding the impact that Haskell's imagery may have on the public is important to investigate. These students suggested this may open avenues for other community members to think "well if they are doing it we can do," but also suggested that if done correctly this imagery could be used to educate and inform the public on Native American culture. Additionally, and more importantly, it appeared that Haskell's imagery, which was not seen as offensive, could be in a sense limiting Native American youth because it represents only certain Native American's and only specific aspects of their culture. The students were concerned with the usage of the headdress because that was only worn for specific religious or cultural reasons and was never typical day-today apparel. This is incredibly important to consider when utilizing Native imagery as scholars have found this imagery is often the only aspect of Native culture many people have knowledge of (Burkley et al., 2017; Fryberg \& Eason, 2017).

Further, the approval of Native mascots has come in large part from individuals who have negative racial attitudes towards Native Americans (Sharrow et al., 2020). Kraus et al. (2019) found that stereotypical mascots reduced donations at universities with people who have low explicit prejudice towards Natives. The students were quite aware that the imagery would have an impact on outsiders, and research has shown that it may be primarily negative or only supported by those who hold these stereotypical thoughts. Therefore, HINU's usage of Native imagery may be even more surprising and the impact on outsiders is important to examine.

If the Native American youth do have negative feelings towards specific Native imagery (Fryberg et al., 2008) and these students felt even relatively appropriate imagery had issues, then Haskell's utilization of Native American imagery and team name is quite puzzling. Counter to this though, these students felt that Haskell's imagery and name, if used appropriately, would be beneficial, potentially empowering, and influential on the perceptions of outsiders. However, that same 2020 survey that found only approximately $50 \%$ of Native Americans affiliated with Haskell thought the mascot should be changed, also found that a vast majority of outsiders surveyed believed the mascot needed to be changed (Nally, 2020). The fact that outsiders may think the mascots should be changed may indicate that multiple steps are needed before it can be used as a vehicle for education. Fryberg and Eason (2017) detailed how detrimental it can be for society to form it's opinions on Native people based on sport mascots, not only because of the stereotypes but everything these mascots and teams omit. Through Native imagery in sport, 
not only do we get an incorrect story, but we only get part of the story.

The finding regarding Haskell students feeling ownership over the Native imagery related to self-representation and the belief that individuals may categorize themselves any way that they want. Students often alluded to Haskell's standing as an all-Native American university. However, scholars who adhere to social representation theory would suggest that even with this "ownership" the imagery could in fact limit what young Native Americans can see in their future selves (Fryberg et al, 2008; Kraus et al., 2019). The students discussed how Native American people are the authority on the issue, and as such provide the public with a reference point as to how they should view the usage of Native American imagery. One issue with this is the fact that these logos and mascots are representing such a broad culture (Peroff \& Wildcat, 2002) which was a concern of these students as they noted the headdress only representing Plains Indians. Despite the ownership and "right" to use Native American imagery, the students felt no imagery or name would represent all $\mathrm{Na}$ tive Americans. Therefore, any usage of Native American imagery is likely going to misinform the public and not represent all students who attend Haskell. The findings of this research further the theory of social representation and provide new insight into this unique case.

\section{Practical Implications}

For professional sport organizations and/or educational institutions who still use Native American imagery, these findings are imperative to developing a further understanding of how Native American people view the usage of this imagery. While this study examined a specific case, the emerging themes should provide practitioners with information regarding how Native American people view the usage of the imagery.

The main theme that might provide practical implications for users of Native American imagery is the perception of overgeneralization and stereotyping of imagery. The students found the more specific and culturally sensitive imagery more appropriate. The more generalized names and imagery, or names associated with the generalized "Indian" or "Native", were found to be improperly used by non-Native people. Students contended that imagery influenced by or implicitly or explicitly approved by Native people was generally more acceptable. Practitioners working for non-Native organizations or institutions, using generalized Native American imagery, without some type of support from Native American people should re-evaluate their usage of their imagery or at least consult Native organizations like others have done (i.e. Florida State).

Specifically, for Haskell Indian $\mathrm{Na}$ tions University, students stated a need for further discussion on the institution's usage of the Fightin' Indians name and their Plains Indian head logo. While students both offered support for and condemnation of Haskell's usage, students also referenced an escalation of dialogue regarding the school's usage of 
the name and imagery. Institutions who are completely or heavily made up of Native American students may consider using Native American imagery as an educational tool. However, this is a slippery slope as it is well documented that what is portrayed, as well as left out on the history of Native American's through sport mascots can hinder Native culture (Fryberg \& Eason, 2017). Specifically, practitioners at Haskell might further evaluate students' perception of the team name and imagery by facilitating this discussion.

\section{Limitations and Future Research}

The main limitation of this research was the small sample size. While data saturation was met in the interview process, more interviews could have been conducted to possibly discover more emerging themes using altered lines of questioning. Also, all of the students interviewed were from one major program, the department of American Indian Studies. This was done to intentionally interview participants with a basic understanding of the issue but interviewing other students within the university could potentially elicit different responses. In general, these students did show a prior fundamental understanding of the issue and this may have influenced their responses.

This inclusion of various students throughout the different departmental programs at Haskell may be a potential area of future research to discover new or unique emerging themes. Further interviews with students may be conduct- ed, or a new methodological approach of gathering data using quantitative methods through the usage of surveys or questionnaires. This different approach could provide a more generalizable understanding of how Haskell students feel about Native American imagery in general and the Haskell usage of Native American imagery in particular.

Future research should be conducted on the varying categorizations of the types of Native American imagery being utilized. The broader approach of understanding the impact of Native American imagery provides important information regarding how an ambiguous group of Native American people view the vague usage of Native American imagery, but the more concise and specific approach of examining the issue in a case by case basis provides a clearer understanding of the issue. Future researchers could focus on specific organizations or institutions and how they impact a specific group of Native American people. This less abstract approach may be able to further develop the personal impact that this issue may or may not have on individual Native Americans.

Additionally, researchers should examine how non-students feel about Haskell's imagery and team name. First, understanding how the Lawrence community feels about Haskell would be beneficial as it would add to the idea that the Haskell student's suggested their imagery may influence the communities feelings. Additionally, it would be interesting to survey Native American's who do not attend Haskell and gather their opinions 
on the imagery utilized by Haskell. The specific case of Haskell still has many avenues for research as does the overall usage of Native American imagery by educational institutions.

\section{Conclusion}

This case study qualitatively explored Haskell Indian Nations University. Through interviews with students at Haskell the authors explored their feelings on Native American imagery overall and how Haskell's usage differed. These students are an excellent conduit to describe the impact of Native American imagery as they represent the only fouryear Native university. Haskell's usage of Native American imagery appeared contradictory before this study, but the interviews shed some light on this.

These students felt Native American imagery usage by sport teams and brands was overall offensive, over-generalized, and stereotypical. Scholars have found Native American's overall would agree with this sediment (Fryberg et al., 2021), but have not addressed all Native institutions usage of Native American imagery. Mascots across sports have been changed because of the misrepresentation of the Native American culture (Schwarb, 2016). Even mascots that are "less offensive" only represent specific Native American culture as the Haskell students brought up regarding headdresses only being worn by plains natives. As we become more informed the tune on Native American imagery has changed and because of this a unique context like Haskell deserves scholar's attention.
Haskell students felt they had a type of ownership over their imagery as they are a university only attended by Native American students. A New York High school, Salamanca central High School Warriors, fought to keep their name and Native imagery partially on the basis that their student body is $26 \%$ Native American (Taylor, 2011). Haskell would have even more of a claim to keep their name and imagery if there was ever a call for change. Despite the ownership over their name and imagery, there was concern about outside perception. As mentioned, their logo wears a headdress which was considered a generalization on Native American people. These generalizations in imagery could further stereotypes (Fryberg et al., 2021; Peroff \& Wildcat, 2002) and potentially misinform the public. Haskell students were worried that others may see their imagery and think that it made it acceptable for them or that all Native Americans wore headdresses.

The unique context of Haskell adds to the literature base as little has been uncovered regarding Native institutions usage of Native American imagery. These institutions create imagery that would likely not be considered appropriation but is still too narrow to be accurate of an entire culture. This research should hopefully lead to further studies addressing how Native imagery may be used by all-Native institutions and further how this representation may have the opportunity to educate the public on Native culture, rather than misrepresent their culture as is regularly seen with 
universities, college athletic departments, and high schools. Additionally, this context could be examined to determine if Haskell's imagery has negative effects on young Natives and other communities. This would be important to understand because if an all-Native university's Native American imagery has negative impacts, it would further discredit other institutions usage of this imagery.

The case of Haskell is incredibly interesting not only because of the uniqueness of the university, but the underlying issues with Native American imagery sport endures today. Scholars have been incredibly adverse, and rightfully so, towards the usage of Native American imagery in general (Fryberg et al., 2021; Fryberg et al., 2008, Steinfeldt \& Wong, 2010), but despite this the students at Haskell felt their ownership and the way the message was construed made their imagery more appropriate. This unique case provided context into Native American usage overall and some contradiction when it came to Haskell's usage. Understanding a situation such as Haskell should aid in scholars overall understanding of the impact of Native American imagery as a whole.

\section{References}

Adams, G., Fryberg, S. A., Garcia, D. M., \& Delgado-Torres, E. U. (2006). The psychology of engagement with indigenous identities: A cultural perspective. Cultural Diversity and Ethnic Minority Psychology , 12, 493-508. Athletic mission \& vision statements. (n.d.). Haskell Athletics. https://www. haskellathletics.com/Athletic_Vision
Bleakley, A., Ellithorpe, M. E., Hennessy, M., Jamieson, P. E., Khurana, A., \& Weitz, I. (2017). Risky movies, risky behaviors, and ethnic identity among Black adolescents. Social Science \& Medicine, 195, 131-137.

Bureau of Indian Education. (n.d.). U.S. Department of Interior Indian Affairs. https://www.bia.gov/bie

Burke, P. J., \& Stets, J. E. (2009). Identity theory. Oxford University Press.

Burkley, M., Burkley, E., Andrade, A., \& Bell, A. C. (2017). Symbols of pride or prejudice? Examining the impact of Native American sports mascots on stereotype application. The Journal of social psychology, 157(2), 223-235.

Callais, T. M. (2010). Controversial mascots: Authority and racial hegemony in the maintenance of deviant symbols. Sociological Focus, 43(1), 61-81.

Carter, M. J., \& Fuller, C. (2015). Symbolic interactionism. Sociopedia.isa, 1(1), 1-17.

Carter, M. J., \& Fuller, C. (2016). Symbols, meaning, and action: The past, present, and future of symbolic interactionism. Current Sociology, 64(6), 931-961.

Davis-Delano, L.R., Gone, J.P., \& Fryberg, S.A. (2020). The psychosocial effects of Native American mascots: a comprehensive review of empirical research findings. Race Ethnicity and Education, 23(5), 613-633.

DeCuir-Gunby, J., Marshall, P., \& McCulloch, A. (2011). Developing and using a codebook for the analysis of interview data: An example from a professional development research project. Field Methods, 23, 136-155. 
Erikson, E.H. (1968). Identity, youth and crisis. W.W. Norton.

Ferguson, G.M., Nguyen, J., \& Iturbide, M.I. (2017). Playing up and playing down cultural identity: Introducing cultural influence and cultural variability. Cultural Diversity and Ethnic Minority Psychology, 23(1), 109-124.

Fisher, S., Zapolski, T. C., Sheehan, C., \& Barnes-Najor, J. (2017). Pathway of protection: Ethnic identity, self-esteem, and substance use among multiracial youth. Addictive behaviors, 72, 27-32.

Fryberg, S.A. \& Eason, A.E. (2017). Making the invisible visible: Acts of commission and omission. Current Directions in Psychological Science, 26(6), 554-559.

Fryberg, S.A., Eason, A.E., Brady, L.M., Jessop, N., Lopez, J.J. (2021). Unpacking the mascot debate: Native American identification predicts opposition to Native mascots. Social Psychological and Personality Science, 12(1), 3-13.

Fryberg, S. A., Markus, H. R., Oyserman, D., \& Stone, J. M. (2008). Of warrior chiefs and Indian princesses: The psychological consequences of American Indian mascots. Basic and Applied Social Psychology , 30, 208-218.

Guba, E. \& Lincoln, Y. (1994). Competing paradigms in qualitative research. In N.K. Denzin \& Y.S. Lincoln (Eds.), Handbook of qualitative research (pp. 105117). Sage Publications.

Hylton, J.G. (2010). Before the Redskins were the Redskins: The use of Native American team names in the forma- tive era of American sports, 1857 1933. NDL Rev., 86, 879-903.

Kelly, C. R. (2017). Representations of Native Americans in the mass media. In Oxford Research Encyclopedia of Communication. Oxford University Press.

King, R.E. (2010). The Native American mascot controversy: A bandbook. Rowman \& Littlefield.

Kim, B. (2010). Social constructivism. In M. Orey (Ed.), Emerging perspectives on learning, teaching, and technology (pp. 5561). The Global Text Project.

Kraus, M. W., Brown, X., \& Swoboda, H. (2019). Dog whistle mascots: native American mascots as normative expressions of prejudice. Journal of Experimental Social Psychology, 84, 103810 Leavitt, P. A., Covarrubias, R., Perez, Y. A., \& Fryberg, S. A. (2015). "Frozen in time": The impact of Native American media representations on identity and self-understanding. Journal of Social Issues, 71(1), 39-53.

Lewis, J. A., Raque-Bogdan, T. L., Lee, S., \& Rao, M. A. (2018). Examining the role of ethnic identity and meaning in life on career decision-making self-efficacy. Journal of Career Development, 45(1), 68-82.

Merriam, S. B. (2009). Qualitative research: A guide to design and implementation. San Francisco: JosseyBass.

Masta, S. (2018). 'I am exhausted:' everyday occurrences of being Native American. International Journal of Qualitative Studies in Education, 31(9), 821-835. 
Moscovici, S. (1998). The history and actuality of social representations. In U. Flick (Ed.), The psychology of the social (pp. 209-247). Cambridge, England: Cambridge University Press.

Morse, J. M., Barrett, M., Mayan, M., Olson, K., \& Spiers, J. (2002). Verification strategies for establishing reliability and validity in qualitative research. International Journal of Qualitative Methods, 1(2), 13-22.

Mullen, B., \& Goethals, G. R. (Eds.). (2012). Theories of group behavior. Springer Science \& Business Media.

Mungia, H. (2014). The 2,128 Native American mascots people aren't talking about. FiveThirtyEight. Retrieved from: http:// fivethirtyeight. $\mathrm{com} /$ features/the-2128-native-american-mascots-people-arent-talkingabout/

Nally, J. (2020, Sept. 25). Change the Mascot? The Indian Leader. http://www.theindianleader. com/2020/09/25/change-the-mas$\cot /$

NCAA Executive Committee. (2005, Aug. 5). Issues Guideline for Use of Native American Mascots at Championship Events. NCAA Press Release Archive. http://fs.ncaa. org/Docs/PressArchive/2005/ Announcements/NCAA\%2BExecutive $\% 2 \mathrm{BCommittee} \% 2 \mathrm{BIs}$ sues $\% 2$ BGuidelines $\% 2 \mathrm{~B}$ for $\%$ 2BUse $\% 2 B$ of $\% 2$ BNative $\% 2 B$ American $\% 2 \mathrm{BMascots} \% 2 \mathrm{Bat} \% 2 \mathrm{BChampi-}$ onship $\% 2$ BEvents.html

Peroff, N. C., \& Wildcat, D. R. (2002). Who is an American Indian? The Social Science Journal, 39, 349-361.
Petty N. J., Thomson O. P., Stew G., (2012). Ready for a paradigm shift? Part 1: Introducing the philosophy of qualitative research. Manual Therapy, 17(4), 267-274

Posten, A., \& Mussweiler, T. (2013). When distrust frees your mind: The stereotype reducing effects of distrust. Journal of Personality and Social Psychology, 4, 567-584.

Schmidt, R. (2001). Lords of the Prairie: Haskell Indian School Football, 1919 1930. Journal of Sport History, 28(3), 403-426.

School history. (n.d.). Haskell Indian Nations University. https://www.haskell. edu/about/history/

Schwarb, A. (2016). Where pride meets prejudice. NCAA Champion Magazine. Retrieved from: http://www.ncaa. org/static/champion/where-pridemeets-prejudice/index.php

Schwartz, S. J., Unger, J. B., Zamboanga, B. L., \& Szapocznik, J. (2010). Rethinking the concept of acculturation: implications for theory and research. American Psychologist, 65(4), 237.

Sharrow, E.A., Tarsi, M.R., \& Nteta, T.M. (2020). What's in a Name? Symbolic racism, public opinion, and the controversy over the NFL's Washington Football team name. Race and Social Problems. DOI: https://doi. org/10.1007/s12552-020-09305-0 Shepard, S.M., Delgado, R.H., Sherwood, J., \& Paradies, Y. (2018). The impact of indigenous cultural identity and cultural engagement on violent offending. BMC Public Health, 18(50). DOI: $10.1186 /$ s12889-017-4603-2 
Staurowsky, E.J. (2007). "You know, we are all Indian" Exploring white power and privilege in reactions to the NCAA Native American mascot policy. Journal of Sport and Social Issues, 31(1), 61-76.

Steinfeldt, J. A., \& Wong, Y. J. (2010). Multicultural Training on American Indian Issues: Testing the Effectiveness of an Intervention to Change Attitudes Toward Native-Themed Mascots. Cultural Diversity and Ethnic Minority Psychology , 16 (2), 110-115.
Taylor, M. (2011). The Salamanca Warriors: A case study of an "exception to the rule." Journal of Anthropological Research, 67, 245-263.

The United States Commission on Civil Rights. (2001, Apr. 13). Commission Statement on the Use of Native American Images and Nicknames as Sports Symbols. https://eric.ed.gov/?id=ED452017 Tongo, M. (2007). Purposive sampling as a tool for informant selection. Ethnobotany Research \& Applications. 5, 147158. 
Appendix 1

Interview Prompt

1. How long have you been a student here?

a. Where did you grow up?

b. How did you hear about Haskell?

2. How do you feel about the usage of Native American imagery for schools and sport teams?

a. Does the usage of Native American imagery impact you personally?

i. Or did it impact you growing up in anyway?

b. Do you care if schools/teams use Native American imagery? Why/ why not?

3. What do you think about these images? (display logos: Indians, Redskins, FSU, ND, etc.)

a. Do any aspects of these images bother you?

b. Do you believe they are an accurate representation of your culture?

c. Do you think this imagery can have a negative impact on you personally or on Native American culture?

4. Are you fully aware of your school's team name and imagery?

a. How does it make you feel?

b. Do you think that it is okay for Haskell to use Native imagery?

5. Do you think there is a difference between Haskell's imagery and any high school/college using similar imagery?

a. What makes Haskell's usage different?

b. Do you think Haskell's usage is an accurate depiction of Native American culture?

6. Do you feel that a Native institution like Haskell has more right to utilize this imagery? (If not brought up organically)

a. Do you think Haskell's usage of the imagery impacts public perception of other institutions using similar imagery?

b. Can it be harmful even if the imagery is used by a Native institution?

7. Do you think the imagery, and way Haskell represents Native culture educates the public?

a. Could it be used to educate?

8. Does it matter to you if a team/school's Native American imagery is accurate of your culture?

a. How can this be beneficial? (Or can it?)

b. In what ways can Native American imagery be useful/positive? (or can it?)

c. Is accurate usage more acceptable to you? 